\title{
A Cusp Catastrophe Model for Satisfaction, Conflict, and Conflict Management in Teams
}

\author{
Isabel Dórdio Dimas ${ }^{1,2} 0000-0003-4481-2644$, Teresa \\ Rebelo $^{3,4} 0000-0003-3380-0840$, Paulo Renato Lourenço ${ }^{3,4} 0000-0003-1405-3835$, \\ and Humberto Rocha ${ }^{5,6} 0000-0002-5981-4469$ \\ 1 ESTGA, Universidade de Aveiro, \\ 3750 - 127 Águeda, Portugal \\ 2 GOVCOPP, Universidade de Aveiro, \\ 3810-193 Aveiro, Portugal \\ 3 IPCDVS, Universidade de Coimbra, \\ 3001-802 Coimbra, Portugal \\ 4 FPCEUC, Universidade de Coimbra, \\ 3000-115, Coimbra, Portugal \\ 5 CeBER and FEUC, Universidade de Coimbra, \\ 3004-512 Coimbra, Portugal \\ 6 INESC-Coimbra, 3030-290 Coimbra, Portugal \\ idimas@ua.pt, terebelo@fpce.uc.pt, \\ prenato@fpce.uc.pt, hrocha@mat.uc.pt
}

\begin{abstract}
Teams are now a structural feature in organizations, and conflict, which is recognized as an inescapable phenomenon in the team context, has become an area of increased research interest. While the literature shows contradictory results regarding the impact of conflicts on teams, the strategies used to manage them have shown that can help to explain the differentiated effects of conflict situations. Adopting a nonlinear dynamic system perspective, this research tests a cusp catastrophe model for explaining team members' satisfaction, considering the roles of conflict and of conflict management. In this model, the conflict type is the asymmetry variable and conflict-handling strategies are the bifurcation variables. The sample is composed of 44 project teams, and data was collected at two points (half-way through and at the end of the project). The presence of a cusp catastrophe structure in the data was tested through both the dynamic difference equation modeling approach, which implements the least squares regression technique, and the indirect method, which uses the maximum likelihood estimation of the parameters. The results suggest that the cusp model is superior to the linear model when the bifurcation variables are passive strategies, while less clear results were found when active strategies are considered. Thus, the findings show a tendency for a nonlinear effect of passive strategies on members' satisfaction. Accordingly, this study contributes to the literature by presenting passive conflict-handling strategies in a bifurcation role, which suggests that beyond a certain threshold of the use of these kind of strategies, teams might oscillate between two attractors.
\end{abstract}

Keywords: Cusp model, Nonlinear analysis, Teams, Satisfaction 


\section{Introduction}

Modern organizations, more than at any other time in history, rely on groups as a way of structuring their activities. The belief that the use of groups is related to improvements in terms of quality, performance and innovation has led to the proliferation of this strategy of organizing the work [1. Assuming that teams are created with the aim of generating value for the organization, a significant part of the research developed in this area has been trying to identify the conditions that contribute to team effectiveness (e.g., 23]). Team effectiveness is a multidimensional construct that integrates several dimensions, ranging from criteria more related to the task system of the team, such as performance or innovation, to criteria that concern the affective system of the team, like the quality of the group experience or satisfaction [45].

According to Hackman [4], team effectiveness can be evaluated through three different dimensions: a) the degree to which the team's results meet, or exceed, the standards of quantity and quality of those who receive, review, and/or use it; b) the extent to which social processes within the team maintain, or enhance, the ability of the group to work together in the future; and c) the degree to which the group experience satisfies the social needs of its members, contributing to an increase in well-being and development. In the present paper, our focus is on the processes that influence team members' satisfaction, which is in line with the third dimension of Hackman's three dimensional approach [4]. Satisfaction with the team can be defined as an affective response from members to the team, to its characteristics and to the way it functions [67. Although organizational teams are created, essentially, with the purpose of achieving task results, their ability to meet the emotional and social needs of their members is extremely important since it affects the functioning of the whole system. Indeed, the literature shows that members' satisfaction with the team may influence team performance 8, as well as team members' willingness to continue to work together in the future 9].

Despite the many advantages associated with the presence of teams in the organizational setting, teamwork can also pose some challenges to individuals and organizations [10]. When individuals are gathered in teams, they have to interact with each other in order to perform the tasks. This interdependence, while being one of the strengths of working in groups, opens the way to disagreements and discussions that are inescapable phenomena in the team context. Accordingly, conflict emerges as a central topic to be studied in order to understand the dynamics, functioning and effectiveness of teams [11. Conflict can be defined as a disagreement that is perceived as creating tension by at least one of the parties involved in an interaction [12].

Over the years, researchers have been trying to clarify the consequences of conflict on team outcomes (e.g., [121314]). Much of this research distinguishes between two types of conflict: task conflict, which encompasses disagreements among team members regarding the work being performed, and affective conflict, which is related to situations of tension between team members caused by differences in terms of personality or values [15]. Although, theories argue 
that, when conflict is focused on the task, can have positive outcomes, these positive effects have been largely elusive [12 16. In fact, empirical results consistently report a negative impact of intragroup conflict on team effectiveness (e.g., [12 13 16]). When the outcome considered is team member's satisfaction, results tend to be even more consistent. Indeed, even if a conflict might be positive for task results because team members gain information about different opinions and perspectives [15, individuals who engage in conflict situations feel frustration and irritation and tend to be less satisfied with their team [13.

To understand the effects of intragroup conflict on team results, particularly on team members' satisfaction, we have to consider the way team members handle conflict situations. At the intragroup level, conflict management strategies describe the responses of team members to conflict situations [11. Although several frameworks exist for classifying conflict management strategies (e.g., [171819]), most of them are based on a two-dimensional typology: one dimension encompasses the extent to which one wants to pursue one's interests (concern for self) and the other dimension concerns the extent to which one wants to fulfill the interest of the other party involved in the interaction (concern for others). From the combination of these two dimensions, five conflict-handling strategies emerge, of which the most studied are: integrating (high concern for self/high concern for others), dominating (high concern for self/low concern for others), avoiding (low concern for self/low concern for others) and obliging (low concern for self/high concern for others) 20. Integrating and dominating are both active strategies of handling conflict. While integrating is a cooperative approach and dominating is a competitive one, when parties adopt these strategies act in an assertive way in order to attain the desired goals. They are in control of their own actions and they try to influence the outcomes obtained from the conflict situation 2122. Avoiding and obliging are passive strategies of managing conflict: when individuals adopt avoiding or obliging strategies to handle conflict situations, they are giving up on their own interests and they behave as passive recipients of their counterpart's actions and initiatives [2123.

Previous studies have tried to clarify how particular ways of managing intragroup conflict influence team effectiveness (e.g., 24|25]). Integrating has been reported as the most constructive way of handling conflict and evidence has been found for its positive effect on team members' satisfaction 1113. However, handling conflict through a collaborative approach may not always be an appropriate strategy. Indeed, previous studies found that certain conflict situations are difficult to settle to mutual satisfaction and being cooperative and understanding in this kind of situations is unlikely to solve the problem, contributing to its escalation 25126. Moreover, integrating is a strategy that consumes time and energy and detracts the team from the task, threatening the ability of the team to achieve its results [25]. This is particularly important when the frequency of conflict is too high. Dominating, in turn, being a win-lose strategy, has been related to negative consequences, such as poor performance and poor levels of satisfaction $13 \mid 27 / 28$. However, although much of the literature presents the dominating strategy as a non-effective way of facing a conflict situation, there is also some 
empirical evidence for the positive consequences of dominating for effectiveness (e.g., 29]). These results are in line with the conflict management contingency approach [18, which assumes that the appropriateness of each conflict-handling strategy depends on the circumstances. Concerning passive strategies of conflict management, the results are even more inconclusive. Indeed, although some studies suggest that adopting a passive strategy of conflict management might be an effective way of handling some kinds of conflict [25, others suggest that the lack of controls in the results obtained that characterizes this kind of strategy tends to increase strain and frustration [21] generating dissatisfaction in the teams.

In the traditional teamwork research literature, low levels of consensus like the one reported above are common. Actually, discrepancies like these ones appear and have been, mainly, treated as irregularities because the linear and reductionist approach is not able to capture the complexity of teams 30 31 32. In order to understand the dynamic nature of teams, one should adopt perspectives and methods that recognize the nonlinear nature of the relationships between team inputs, processes and outcomes [33. Accordingly, the central aim of the present paper is to examine team members' satisfaction from a nonlinear dynamical system (NDS) perspective taking into account the role played by conflict and conflict management.

The NDS approach is the study of how complex processes unfold over time and is sometimes known as chaos theory or complexity theory [34]. One branch of complexity science, catastrophe theory, which is based on nonlinear modeling methods, enables the analysis of discontinuous, abrupt changes in dependent variables resulting from small and continuous changes in independent variables 35. Cusp catastrophe theory, the most commonly used in team research, describes change between two stable states of the dependent variable (i.e., order parameter) and two independent variables (i.e., control parameters) [36]. The possibility of modeling discontinuous changes, richly describing the phenomenon under consideration [37, is one advantage of this approach that can contribute to the development of the knowledge about the complex relationships between conflict, conflict management and satisfaction.

The purpose of the present paper is to test a cusp model in the data, which is summarized in Fig. 1. Members' satisfaction is considered the dependent variable or the order parameter, which is influenced by intragroup conflict and conflict management. Based on the literature presented above, it is expected that intragroup conflict will maintain a negative and stable relationship with members' satisfaction, because the higher the level of task and affective conflict within the team, the lower the level of satisfaction of the members with the team. Thus, members' satisfaction is considered as the asymmetry variable in the cusp model since this type of parameter is related to the order parameter in a consistent pattern 37. Conflict management, in turn, is a potential candidate for a bifurcation parameter, inasmuch as it could lead the group system to a sudden change in level of satisfaction. Hence, the inconsistent pattern of results concerning the relationship between conflict-handling strategies and satisfaction might be a clue 


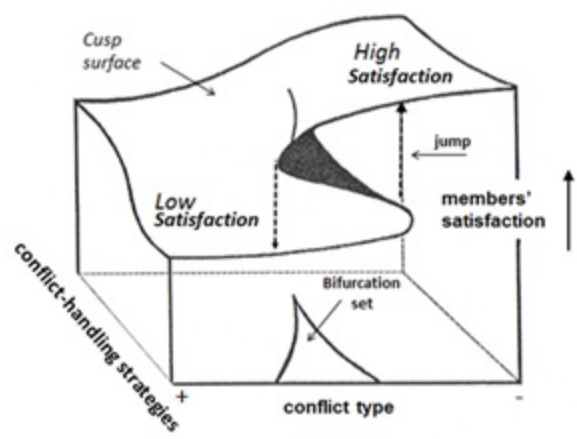

Fig. 1. A three-dimensional display of the cusp catastrophe response surface of members' satisfaction as a function of type of conflict (asymmetry) and conflict-handling strategies (bifurcation).

for the presence of a nonlinear relationship still unknown. A certain amount of each of the conflict-handling strategies might be beneficial, allowing the group to manage the conflict situations in an effective way, leading, consequently, to positive feelings towards the group. However, a high frequency of use of each of the strategies mentioned might be dysfunctional: active strategies might contribute to an escalation of conflict, with negative consequences for team results, while passive strategies might lead to an increase in the levels of frustration, jeopardizing the levels of satisfaction. Consequently, conflict-handling strategies is a potential candidate for a bifurcation parameter, since it might lead team members to a sudden change in level of satisfaction.

\section{Materials and Methods}

\subsection{Sample}

A longitudinal study was conducted in which we surveyed project teams from technological and engineering programs of one Portuguese university. These undergraduate programs are organized in a Project-Based Learning (PBL) environment. Within this framework, students are asked to develop, in small groups (between three and six members), real-life challenges that are presented to them as projects. Students have one semester to develop their projects and, when needed, professors can guide them, acting as facilitators.

Data was collected in a meeting with each team at two points in the semester: at the middle of the academic semester (T1) and at the end of the semester (T2), before the public presentation of the work developed. At T1 participants were asked about what had happened in the team since the beginning of the group until the moment they filled in the questionnaire and at T2 students were asked 
to evaluate the group according to what had happened since the previous data collection. Forty-four project groups participated in the data collection. Teams had, on average, four members $(\mathrm{SD}=0.9)$, with a mean age of 24 years $(\mathrm{SD}=$ $6.5), 88 \%$ were male, $78 \%$ were full time students and most of them $(55 \%)$ were attending the third year of the program $(31 \%$ were attending the first year and the remaining the second year).

\subsection{Measures}

In the present study, all constructs under study (i.e., members' satisfaction with the team, intragroup conflict and conflict management) were measured through single-item measures and VAS (Visual Analogue Scales). In the case of conflict and conflict management since they are multidimensional constructs, a single-item measure was created for each dimension. Our decision to use this kind of measures is in line with the guidelines of authors such as Roe, Gockel and Meyer [38, which state that multi-item measures are not appropriate for capturing change in groups over time and that single-item measures and graphic scales are suitable alternatives in longitudinal studies.

All measures were submitted to a set of experts and to three pilot studies for estimating content and face validities, respectively, and no problems have been identified [39]. Convergent validity studies with the original multi-item measures on which these measures were based, as well as nomological validity studies, were also conducted in order to support our confidence in the measures used 40141.

To measure members' satisfaction with the team, we developed one singleitem that assesses the overall satisfaction with the team. The development of this item was based on the Gladstein's Global Satisfaction Scale [42, which is composed of three items. Participants were asked to mark on a VAS, from 0 (very dissatisfied) to 10 (very satisfied), the degree of satisfaction, or dissatisfaction, with the team, at the two data collection points.

To measure intragroup conflict, two items were developed based on the 9item scale by Dimas and Lourenço [13: one item for assessing task conflict and the other one for measuring affective conflict. Participants were asked, at T1, to mark on a VAS, from 0 (never) to 10 (always), the frequency of the occurrence of tension related to the way the work should be performed (task conflict) and to differences of personality or values between members (affective conflict).

To measure conflict management, four single-item measures were developed based on the ROCI-II multi-item scale 43. Participants were asked to mark on a VAS, from 0 (never) to 10 (always), the frequency of adopting each of the four conflict management strategies in order to handle conflict situations, from the beginning of the project to the data collection point (T1).

\subsection{Data Analysis}

Mathematically, the cusp model is expressed by a potential function $f(y)$ :

$$
f(y / a, b)=a y+\frac{1}{2} b y^{2}-\frac{1}{4} y^{4} .
$$


Equation (1) represents a dynamical system, which is seeking to optimize some function 4445. Setting the first derivative of the equation (1) to zero, it results in the equation (2), which represents the three-dimensional equilibrium response surface of the cusp model:

$$
\frac{\delta f(y)}{\delta y}=0 \Leftrightarrow-y^{3}+b y+a=0,
$$

where $a$ is the asymmetry factor and $b$ is the bifurcation factor.

In the present research design, the teams began to work at time T0 (not measured), while two measurements were carried out at the middle of teams' life (T1) and at the end of the teams' life (T2). These two measures in time facilitate the application of the dynamic difference equation modeling approach, which implements least squares regression techniques [46. According to this method all variables were transformed to $z$ scores corrected for location and scale :

$$
z=\frac{y-\lambda}{s},
$$

where $\lambda$ is the minimum value of $y$ and the scale $s$ is the ordinary standard deviation. The specific equation to be tested for a cusp catastrophe model is:

$$
\delta z=z_{2}-z_{1}=b_{1} z_{1}^{3}+b_{2} z_{1} C H S+b_{3} C+b_{4}
$$

where $z$ is the normalized behavioral variable, while $C$ and $C H S$ are the normalized asymmetry (conflict) and the bifurcation (conflict-handing strategies), respectively. The nonlinear model is tested against its linear alternatives, from which the most antagonistic is the pre/post model:

$$
z_{2}=b_{1} C H S+b_{2} C+b_{3} z_{1}+b_{4} .
$$

For both models, $z_{1}$ is team members' satisfaction at T1 while at T2 is $z_{2}$ and $b_{i}, i=1, \ldots, 4$ are the model's parameters to be determined by least squares regression.

In order to test the nonlinear hypothesis that a cusp catastrophe is appropriate model to describe satisfaction, the regression equation (4) should account for a larger percent of the variance in the dependent variable than the linear alternatives. In addition, the coefficients of both the cubic and the product terms in equation (4) must be statistically significant.

Moreover, additional calculations were carried out with the indirect method, which implements the cusp pdf and uses maximum likelihood estimation of the parameters 47 . The calculations are performed in $\mathrm{R}$ cusp package. In this method, the statistical evaluation model fit was based on pseudo- $\mathrm{R}^{2}$ statistics for the cusp models and on AIC, AICc and BIC indices (Akaike's criterion, Akaike's criterion corrected for small samples and Bayes's information criterion, respectively). Also the likelihood ratio chi-square was used in order to compare the fit of the cusp models and the linear regression models [37. In addition, the presence of a cusp catastrophe is established by the statistical significance of its coefficients. 
Table 1. Means, standard deviations, and intercorrelations of study variables.

\begin{tabular}{lcccccccccc}
\hline & Mean SD & 1 & 2 & 3 & 4 & 5 & 6 & 7 & 8 \\
\hline 1. Task conflict T1 & 2.91 & 1.95 & - & - & - & - & - & - & - & - \\
2. Affective conflict T1 & 2.24 & 2.05 & $.69^{* *}$ & - & - & - & - & - & - & - \\
3. Avoiding T1 & 3.99 & 1.79 & $.27^{*}$ & $.26^{*}$ & - & - & - & - & - & - \\
4. Integrating T1 & 7.66 & 1.32 & $-.28^{*}$ & $-.32^{*}$ & .20 & - & - & - & - & - \\
5. Obliging T1 & 5.93 & 1.32 & $-.40^{*}$ & $-.26^{*}$ & -.05 & $.32^{*}$ & - & - & - & - \\
6. Dominating T1 & 2.51 & 1.44 & $.51^{* *}$ & $.59^{* *}$ & $.42^{* *}$ & -.18 & -.10 & - & - & - \\
7. Satisfaction T1 & 7.25 & 2.20 & .05 & -.04 & .12 & $.47^{* *}$ & .02 & -.06 & - & - \\
8. Satisfaction T2 & 7.64 & 1.72 & -.18 & -.07 & -.13 & .20 & .01 & -.06 & $.45^{* *}$ & - \\
\hline
\end{tabular}

Note: ${ }^{* *} \mathrm{p}<.01,{ }^{*} \mathrm{p}<.05$.

\section{Results}

As the unit of analysis in the present study was the group rather than the individual, members' responses were aggregated to the team level for further analyses. In order to justify the aggregation of the team level constructs (conflict type and conflict-handling strategies), the ADM index [48] was used. The average ADM values obtained for task conflict, affective conflict, integrating, dominating, avoiding and obliging were, respectively, 1.13 (SD =0.87), $0.99(\mathrm{SD}=0.88), 1.0$ $(\mathrm{SD}=0.93), 1.27(\mathrm{SD}=.85), 1.7(\mathrm{SD}=1.09), 1.26(\mathrm{SD}=0.87)$. Since all the values were below the upper-limit criterion of 2.0, team members' scores were aggregated, with confidence, to the team level.

Table 1 displays the means, standard deviations and correlations for all variables under study. Tables 2 to 5 show the regression slopes, standard errors and t-tests for four cusp catastrophe models and their pre/post linear models. Table 2 shows the results for the difference model estimated by least squares regression, with task and affective conflicts as asymmetry variables and integrating as a bifurcation variable. The cusp model and the pre/post linear explain a similar proportion of the variance $\left(\mathrm{R}^{2}=.27\right)$, and, in the cusp model, only the cubic term is significant $[\mathrm{t}=-2.52, \mathrm{p}<0.05]$. Table 3 , in turn, shows the results for the difference model estimated by least squares regression, with task and affective conflicts as asymmetry variables and dominating as a bifurcation variable. Results revealed that the cusp model explains a smaller proportion of the variance $\left(\mathrm{R}^{2}=.25\right)$ compared to the pre/post linear model $\left(\mathrm{R}^{2}=.26\right)$. In the cusp model, the cubic term $[\mathrm{t}=-2.93, \mathrm{p}<0.01]$ and task conflict $[\mathrm{t}=-1.79, \mathrm{p}<0.10]$ were significant. Table 4 displays the model fit for the difference model estimated by least squares regression, with task and affective conflicts as asymmetry variables and obliging as a bifurcation variable. The cusp model is superior to the pre/post 
Table 2. The difference model estimated by least squares regression: Slopes, Standard Errors and t-tests for Cusp and the Linear Control. Integrating as bifurcation variable.

\begin{tabular}{|c|c|c|c|c|c|c|}
\hline Model & Variable name & $\mathbf{R}^{2}$ & B & SEB & $\beta$ & $\mathbf{t}$ \\
\hline Pre/Post & & $.27^{*}$ & & & & \\
\hline $\mathrm{z}_{1}$ & Satisfaction & & 0.52 & 0.16 & .52 & $3.34^{* *}$ \\
\hline $\mathrm{b}$ & Integrating & & 0.08 & 0.17 & -.08 & -0.48 \\
\hline $\mathrm{a}$ & Task conflict & & -0.34 & 0.19 & .34 & $-1.73^{\dagger}$ \\
\hline $\mathrm{a}$ & Affective conflict & & 0.16 & 0.19 & .16 & 0.84 \\
\hline Cusp 1 & & $.27^{*}$ & & & & \\
\hline $\mathrm{z}_{1}^{3}$ & Satisfaction & & -0.07 & 0.03 & -.36 & $-2.52^{*}$ \\
\hline $\mathrm{b}$ & Integrating & & 0.22 & 0.22 & .22 & 1.59 \\
\hline $\mathrm{a}$ & Task conflict & & -0.30 & -0.29 & -.29 & -1.51 \\
\hline a & Affective conflict & & 0.23 & .22 & .22 & 1.17 \\
\hline
\end{tabular}

Note: ${ }^{* *} \mathrm{p}<.01,{ }^{*} \mathrm{p}<.05,{ }^{\dagger} \mathrm{p}<.10$.

Table 3. The difference model estimated by least squares regression: Slopes, Standard Errors and t-tests for Cusp and the Linear Control. Dominating as bifurcation variable.

\begin{tabular}{|c|c|c|c|c|c|c|}
\hline Model & Variable name & $\mathbf{R}^{2}$ & B & SEB & $\beta$ & $\mathbf{t}$ \\
\hline Pre/Post & & $.26^{*}$ & & & & \\
\hline $\mathrm{z}_{1}$ & Satisfaction & & 0.48 & 0.14 & .48 & $3.46^{* *}$ \\
\hline $\mathrm{b}$ & Integrating & & 0.05 & 0.17 & .05 & 0.26 \\
\hline $\mathrm{a}$ & Task conflict & & -0.33 & 0.20 & -.33 & $-1.70^{\dagger}$ \\
\hline $\mathrm{a}$ & Affective conflict & & 0.16 & 0.21 & .16 & 0.77 \\
\hline Cusp 1 & & $.25^{*}$ & & & & \\
\hline $\mathrm{z}_{1}^{3}$ & Satisfaction & & -0.09 & 0.03 & -.50 & $-2.93^{* *}$ \\
\hline $\mathrm{b}$ & Integrating & & -0.18 & 0.15 & -.22 & -1.14 \\
\hline $\mathrm{a}$ & Task conflict & & -0.37 & 0.21 & -.35 & $-1.79^{\dagger}$ \\
\hline $\mathrm{a}$ & Affective conflict & & 0.22 & 0.21 & .21 & 1.05 \\
\hline
\end{tabular}

Note: ${ }^{* *} \mathrm{p}<.01,{ }^{*} \mathrm{p}<.05,{ }^{\dagger} \mathrm{p}<.10$.

linear by explaining a larger portion of the variance $\left(\mathrm{R}^{2}=.47\right)$, while the cubic term $[\mathrm{t}=-4.64, \mathrm{p}<0.001]$, the bifurcation $[\mathrm{t}=4.29, \mathrm{p}<0.001]$ and the asymmetry task conflict $[\mathrm{t}=-2.08, \mathrm{p}<0.05]$ are statistically significant. Similarly, Table 5 gives the model fit for the difference model with task and affective conflicts as asymmetry variables and avoiding as a bifurcation variable. Results reveal that the cusp model is superior to the pre/post linear by explaining a larger proportion of the variance $\left(\mathrm{R}^{2}=.29\right)$, while the cubic term $[\mathrm{t}=-3.19, \mathrm{p}<0.01]$, the bifurcation $[\mathrm{t}=1.87, \mathrm{p}<0.10]$ and the asymmetry task conflict $[\mathrm{t}=-1.91, \mathrm{p}$ $<0.10]$ are statistically significant. The above cusp analyses support the role of 
Table 4. The difference model estimated by least squares regression: Slopes, Standard Errors and t-tests for Cusp and the Linear Control. Obliging as bifurcation variable.

\begin{tabular}{|c|c|c|c|c|c|c|}
\hline Model & Variable name & $\mathbf{R}^{2}$ & B & SEB & $\beta$ & $\mathbf{t}$ \\
\hline Pre/Post & & $.27^{*}$ & & & & \\
\hline $\mathrm{z}_{1}$ & Satisfaction & & 0.48 & 0.14 & .48 & $3,49^{* *}$ \\
\hline $\mathrm{b}$ & Integrating & & -0.10 & 0.15 & -.10 & -0.67 \\
\hline $\mathrm{a}$ & Task conflict & & -0.37 & 0.20 & -.37 & $-1.81^{\dagger}$ \\
\hline $\mathrm{a}$ & Affective conflict & & 0.18 & 0.19 & .18 & 0.95 \\
\hline Cusp 1 & & $.47^{* * *}$ & & & & \\
\hline $\mathrm{z}_{1}^{3}$ & Satisfaction & & -0.11 & 0.02 & -.59 & $-4.64^{* * *}$ \\
\hline $\mathrm{b}$ & Integrating & & 0.32 & 0.07 & .54 & $4.29^{* * *}$ \\
\hline $\mathrm{a}$ & Task conflict & & -0.35 & 0.17 & -.34 & $-2.08^{*}$ \\
\hline $\mathrm{a}$ & Affective conflict & & 0.24 & 0.17 & .23 & 1.42 \\
\hline
\end{tabular}

Note: ${ }^{* * *} \mathrm{p}<.001,{ }^{*} \mathrm{p}<.01,{ }^{*} \mathrm{p}<.05,^{\dagger} \mathrm{p}<.10$.

Table 5. The difference model estimated by least squares regression: Slopes, Standard Errors and t-tests for Cusp and the Linear Control. Avoiding as bifurcation variable.

\begin{tabular}{|c|c|c|c|c|c|c|}
\hline Model & Variable name & $\mathbf{R}^{2}$ & B & SEB & $\beta$ & $\mathrm{t}$ \\
\hline Pre/Post & & $.28^{*}$ & & & & \\
\hline $\mathrm{z}_{1}$ & Satisfaction & & 0.50 & 0.14 & .50 & $3.60^{* *}$ \\
\hline $\mathrm{b}$ & Integrating & & -0.15 & 0.14 & -.15 & -1.08 \\
\hline $\mathrm{a}$ & Task conflict & & -0.30 & 0.19 & -.30 & -1.56 \\
\hline $\mathrm{a}$ & Affective conflict & & 0.20 & 0.19 & .20 & 1.05 \\
\hline Cusp 1 & & $.29^{* *}$ & & & & \\
\hline $\mathrm{z}_{1}^{3}$ & Satisfaction & & -0.08 & 0.03 & -.45 & $-3.19^{* *}$ \\
\hline $\mathrm{b}$ & Integrating & & -0.22 & 0.12 & -.27 & $-1.87^{\dagger}$ \\
\hline $\mathrm{a}$ & Task conflict & & -.38 & 0.20 & -.36 & $-1.91^{\dagger}$ \\
\hline $\mathrm{a}$ & Affective conflict & & 0.26 & 0.20 & .25 & 1.33 \\
\hline
\end{tabular}

Note: ${ }^{*} \mathrm{p}<.01,{ }^{*} \mathrm{p}<.05,{ }^{\dagger} \mathrm{p}<.10$ (one-tailed).

conflict management (in particular, avoiding and obliging) as bifurcations and exemplified the special role that they might have for team functioning.

In order to find further support for the cusp structure identified, the cusp model was also estimated by maximum likelihood method. Tables 6 to 9 show the slopes, standards errors, $Z$-tests and model fit statistics for the cusp and the linear model. Table 6 displays the estimated cusp model with types of conflict as the asymmetry variables and integrating as the bifurcation variable. As can be seen, the cusp model is superior to the linear one, although the difference is not significant $\left(\chi^{2}(2)=4.34, \mathrm{~ns}\right)$, and task conflict and integrating were both 
Table 6. The cusp model estimated by maximum likelihood method: Slopes, Standard Errors, $Z$-tests and Model Fit statistics for the cusp and the linear model. Members' satisfaction (T2-T1) as dependent variable, types of conflict as asymmetry variables and integrating as bifurcation variable.

\begin{tabular}{|c|c|c|c|c|}
\hline Model & & b & SEB & $Z$-value \\
\hline \multicolumn{5}{|l|}{ Cusp 1} \\
\hline $\mathrm{w}$ & Members' satisfaction & 0.28 & 0.04 & $7.57 * * *$ \\
\hline $\mathrm{a}$ & Task conflict & -1.82 & 0.76 & $-2.39^{*}$ \\
\hline $\mathrm{a}$ & Affective conflict & 0.69 & 0.82 & 0.85 \\
\hline $\mathrm{b}$ & Integrating & 0.55 & 0.24 & $2.29^{*}$ \\
\hline \multicolumn{5}{|c|}{ Models' fit statistics } \\
\hline Models & $\mathrm{R}^{2}$ & AIC & $\mathrm{AICc}$ & $\mathrm{BIC}$ \\
\hline Linear model & .18 & 128.59 & 130.17 & 137.51 \\
\hline Cusp model & .20 & 128.25 & 131.36 & 140.74 \\
\hline
\end{tabular}

Note: ${ }^{* * *} \mathrm{p}<.001,{ }^{*} \mathrm{p}<.05$.

Table 7. The cusp model estimated by maximum likelihood method: Slopes, Standard Errors, $Z$-tests and Model Fit statistics for the cusp and the linear model. Members' satisfaction (T2-T1) as dependent variable, types of conflict as asymmetry variables and dominating as bifurcation variable.

\begin{tabular}{lcccc}
\hline Model & & $\mathrm{b}$ & SEB & $Z$-value \\
\hline Cusp 1 & & & & \\
$\mathrm{w}$ & Members' satisfaction & 0.42 & 0.09 & $4.74^{* * *}$ \\
$\mathrm{a}$ & Task conflict & -1.00 & 0.56 & $-1.78^{\dagger}$ \\
$\mathrm{a}$ & Affective conflict & 0.41 & 0.68 & 0.61 \\
$\mathrm{~b}$ & Integrating & -1.51 & 2.68 & -0.39 \\
Models' fit statistics & & & & \\
Models & $\mathrm{R}^{2}$ & $\mathrm{AIC}$ & $\mathrm{AICc}$ & $\mathrm{BIC}$ \\
Linear model & .08 & 133.88 & 135.46 & 142.80 \\
Cusp model & .12 & 134.04 & 137.15 & 146.53 \\
\hline
\end{tabular}

Note: ${ }^{* *} \mathrm{p}<.001,^{\dagger} \mathrm{p}<.10$ (one-tailed)

statistically significant. Table 7 , in turn, gives the estimated cusp model with types of conflict as the asymmetry variables and dominating as the bifurcation variable. The cusp model was superior to the linear model but the difference was not statistically significant $\left(\chi^{2}(2)=3.84, \mathrm{~ns}\right)$. The role of dominating as a bifurcation variable was also not statistically significant. Table 8 displays the results for the cusp model with types of conflict as the asymmetry variables and obliging as the bifurcation variable. Results support the superiority of the cusp model when compared to the linear one. Indeed, the $\mathrm{R}^{2}$ of the cusp model 
Table 8. The cusp model estimated by maximum likelihood method: Slopes, Standard Errors, $Z$-tests and Model Fit statistics for the cusp and the linear model. Members' satisfaction (T2-T1) as dependent variable, types of conflict as asymmetry variables and obliging as bifurcation variable.

\begin{tabular}{lcccc}
\hline Model & & b & SEB & $Z$-value \\
\hline Cusp 1 & Members' satisfaction & 0.45 & 0.07 & $6.14^{* * *}$ \\
$\mathrm{w}$ & Task conflict & -0.69 & 0.47 & $-1.45^{*}$ \\
$\mathrm{a}$ & Affective conflict & 0.45 & 0.45 & 1.01 \\
$\mathrm{a}$ & Integrating & -2.38 & 1.01 & $2.35^{*}$ \\
$\mathrm{~b}$ & & & & \\
Models' fit statistics & $\mathrm{R}^{2}$ & $\mathrm{AIC}$ & $\mathrm{AICc}$ & $\mathrm{BIC}$ \\
Models & .09 & 133.43 & 135.01 & 142.35 \\
Linear model & .11 & 128.25 & 134.19 & 143.57 \\
Cusp model & & & & \\
\hline
\end{tabular}

Note: ${ }^{* * *} \mathrm{p}<.001,{ }^{*} \mathrm{p}<.05$.

Table 9. The cusp model estimated by maximum likelihood method: Slopes, Standard Errors, $Z$-tests and Model Fit statistics for the cusp and the linear model. Members' satisfaction (T2-T1) as dependent variable, types of conflict as asymmetry variables and avoiding as bifurcation variable.

\begin{tabular}{lcccc}
\hline Model & & b & SEB & $Z$-value \\
\hline Cusp 1 & & & & \\
$\mathrm{w}$ & Members' satisfaction & 0.45 & 0.09 & $5.22^{* * *}$ \\
$\mathrm{a}$ & Task conflict & -0.63 & 0.49 & -1.28 \\
$\mathrm{a}$ & Affective conflict & 0.41 & 0.51 & 0.80 \\
$\mathrm{~b}$ & Integrating & 2.38 & 1.43 & $1.66^{\dagger}$ \\
Models' fit statistics & & & & \\
Models & $\mathrm{R}^{2}$ & $\mathrm{AIC}$ & $\mathrm{AICc}$ & $\mathrm{BIC}$ \\
Linear model & .11 & 132.60 & 134.17 & 141.52 \\
Cusp model & .10 & 129.09 & 132.21 & 141.58 \\
\hline
\end{tabular}

Note: ${ }^{* * *} \mathrm{p}<.001,{ }^{\dagger} \mathrm{p}<.10$ (one-tailed)

$\left(\mathrm{R}^{2}=.11\right)$ was superior to the linear model $\left(\mathrm{R}^{2}=.09\right)$, and the difference was significant $\left(\chi^{2}(2)=6.35, \mathrm{p}<.05\right)$. Moreover, the estimates of fit AIC, AICc and $\mathrm{BIC}$ also recommend the superiority of the cusp model. The role of obliging as bifurcation was significant, as well as the role of task conflict as the asymmetry variable. Finally, Table 9 shows the estimated cusp model with types of conflict as the asymmetry variables and avoiding as the bifurcation variable. Although the role of avoiding as bifurcation was marginally significant, the linear model 
$\left(\mathrm{R}^{2}=.11\right)$ was significantly superior $\left(\chi^{2}(2)=7.50, \mathrm{p}<.05\right)$ to the cusp model $\left(\mathrm{R}^{2}=.10\right)$.

Overall, results obtained with the difference model estimated by least squares regression and with the indirect model estimated by maximum likelihood method, go in the same direction, revealing the existence of a cusp structure in our data, where the role of task conflict as an asymmetry variable and of conflict management, in particular of the obliging strategy, is clearly supported.

\section{Discussion and Conclusions}

Teams have been theoretically conceived as complex, adaptive and dynamic systems: a) complex, because they are entities embedded in a hierarchy of levels revealing complex behaviours; b) adaptive, because they are continuously adapting to environmental changes; and c) dynamic, due to their functioning being dependent both on the team's history and on its anticipated future 949. Despite the general acceptance of teams as complex adaptive systems, the examples of empirical research that incorporate this conceptualization remain scarce [32]. The present paper intends to be a contribution to understanding the complexity of team dynamics, by studying members' satisfaction with the team from a nonlinear dynamic system perspective, taking into account the role played by conflict and conflict management.

With regard to intragroup conflict, in line with the literature [12[13, task conflict presented a negative linear effect on satisfaction, whereas the role of affective conflict was not significant. Because conflict generates tension and discomfort, it is not surprising that team members are less satisfied with being a part of teams where conflicts are very frequent. The non-significant relationship between affective conflict and satisfaction might be due to the fact that we are studying groups that are created to develop a task and, in consequence, the task system is the most prevalent [13.

Conflict-handling strategies act as bifurcation variables exhibiting a "moderating" role with nonlinear effects. As a result, sudden shifts between different modes of satisfaction (high or low) might occur, beyond a threshold value. From the conflict-management strategies that were studied, the role of passive strategies as bifurcation variables, in particular the strategy of obliging, was better supported by the data. Beyond a certain threshold of obliging, groups that have the same level of conflict might oscillate between two attractors, the modes of high and low satisfaction levels, respectively. A small variation in obliging leads the system to an area of unpredictability in terms of members' satisfaction. Thus, the present research contributes to the literature by presenting conflict management as a bifurcation, which might explain the discrepancies between findings about the relationship between passive strategies of conflict-handling and team effectiveness [21 25].

Another contribution of the present paper is the use of both the difference equation modeling approach, which implements the least squares regression technique, and the indirect method, which uses the maximum likelihood estimation 
of the parameters, in order to test the presence of a cusp model. By going in the same direction, the results found with the two methods reinforce the presence of a cusp structure in our data. Moreover, the results reveal that both the difference equation modeling approach and the indirect method are appropriate strategies to use with this kind of data.

The present study, supporting the nonlinear dynamics of conflict, conflict management and satisfaction, adds to the growing body of research that considers teams as complex adaptive and dynamic systems. Despite the contributions of our research, the present work also presents limitations. An important shortcoming of this study is the sample size, which does not allow the simultaneous testing of the four conflict-handling strategies as bifurcation within a cusp model. Moreover, our study is focused on a particular type of group: project groups composed of students. Future studies should replicate the present findings with different teams, such as organizational workgroups.

Acknowledgments. This work was supported by the Fundação para a Ciência e a Tecnologia (FCT) under project grants UID/MULTI/00308/2013 and POCI-01-0145FEDER-008540.

\section{References}

1. Salas, E., Stagl, K.C., Burke, C.S.: 25 Years of Team Effectiveness in Organizations: Research Themes and Emerging Needs. International Review of Industrial and Organizational Psychology 19, 47-91 (2005)

2. Ilgen, D.R., Hollenbeck, J.R., Johnson, M., Jundt, D.: Teams in organizations: from input-process-output models to IMOI models. Annu. Rev. Psychol. 56, 517-543 (2005)

3. Marks, M.A., Mathieu, J.E., Zaccaro, S.J.: A temporally based framework and taxonomy of team processes. Acad. Manag. Rev. 26, 356-376 (2001)

4. Hackman, J.R.: The design of work teams. In: Lorsch, J. (ed.) Handbook of Organizational Behavior, pp. 315-342. Prentice Hall, Englewood Cliffs (1987)

5. Aubé, C., Rousseau, V.: Team goal commitment and team effectiveness: The role of task interdependence and supportive behaviors. Gr. Dyn. 9, 189-204 (2005)

6. Wiiteman, H.: Group Member Satisfaction: A Conflict-Related Account. Small Gr. Res. 22, 24-58 (1991)

7. Dimas, I.D., Lourenço, P.R., Rebelo, T.: Scale of satisfaction with the working group: Construction and validation studies. Av. en Psicol. Latinoam. 36, 197-210 (2018)

8. Lester, S.W., Meglino, B.M., Korsgaard, M.A.: The antecedents and consequences of group potency: A longitudinal investigation of newly formed work groups. Acad. Manag. J. 45, 352-368 (2002)

9. Sundstrom, E., De Meuse, K.P., Futrell, D.: Work teams: Applications and effectiveness. Am. Psychol. 45, 120-133 (1990)

10. Aubé, C., Rousseau, V.: Counterproductive behaviors: Group phenomena with team-level consequences. Team Perform. Manag. An Int. J. 20, 202-220 (2014)

11. DeChurch, L.A., Marks, M.A.: Maximizing the benefits of task conflict: the role of conflict management. Int. J. Confl. Manag. 12, 4-22 (2001) 
12. De Dreu, C.K.W., Weingart, L.R.: Task versus relationship conflict, team performance, and team member satisfaction: A meta-analysis. J. Appl. Psychol. 88, 741-749 (2003)

13. Dimas, I.D., Lourenço, P.R.: Intragroup Conflict and Conflict Management Approaches as Determinants of Team Performance and Satisfaction: Two Field Studies. Negot. Confl. Manag. Res. 8, 174-193 (2015)

14. Shaw, J.D., Zhu, J., Duffy, M.K., Scott, K.L., Shih, H.A., Susanto, E.: A Contingency Model of Conflict and Team Effectiveness. J. Appl. Psychol. 96, 391-400 (2011)

15. Jehn, K.A.: A Multimethod Examination of the Benefits and Detriments of Intragroup Conflict. Adm. Sci. Q. 40, 256 (1995)

16. De Wit, F.R.C., Greer, L.L., Jehn, K.A.: The paradox of intragroup conflict: A meta-analysis. J. Appl. Psychol. 97, 360-390 (2012)

17. Deutsch, M.: The Resolution of Conflict: Constructive and Destructive Processes. American Behavioral Scientist 17, 248-248 (1973)

18. Thomas, K.W.: Conflict and conflict management: Reflections and update. J. Organ. Behav. 13, 265-274 (1992)

19. Rahim, M.A.: A Strategy for Managing Conflict in Complex Organizations. Hum. Relations 38, 81-89 (1985)

20. Kuhn, T., Poole, M.S.: Do Conflict Management Styles Affect Group Decision Making? Evidence From a Longitudinal Field Study. Hum. Commun. Res. 26, 558-590 (2000)

21. Dijkstra, M.T.M., de Dreu, C.K.W., Evers, A.,van Dierendonck, D.: Passive responses to interpersonal conflict at work amplify employee strain. Eur. J. Work Organ. Psychol. 18, 405-423 (2009)

22. van de Vliert, E., Euwema, M. C.: Agreeableness and activeness as components of conflict behaviors. J. Per. Soc. Psychol. 66, 674-687 (1994)

23. van de Vliert, E., Euwema, M.C., Huismans, S.E.: Managing conflict with a subordinate or a superior: Effectiveness of conglomerated behavior. J. Appl. Psychol. 80, 271-281 (1995)

24. Alper, S., Tjosvold, A., Law, K.S.: Conflict management, efficacy, and performance in organisational teams. Pers. Psychol. 53, 625-642 (2000)

25. De Dreu, C.K.W., Van Vianen, A.E.M.: Managing relationship conflict and the effectiveness of organizational teams. J. Organ. Behav. 22, 309-328 (2001)

26. Murnighan, J.K., Conlon, D.E.: The Dynamics of Intense Work Groups: A Study of British String Quartets. Adm. Sci. Q. 36, 165-186 (1991)

27. Behfar, K.J., Peterson, R.S., Mannix, E.A., Trochim, W.M.K.: The Critical Role of Conflict Resolution in Teams: A Close Look at the Links Between Conflict Type, Conflict Management Strategies, and Team Outcomes. J. Appl. Psychol. 93, 170188 (2008)

28. Friedman, R.A., Tidd, S.T., Currall, S.C., Tsai, J.C.: What goes around comes around: the impact of personal conflict style on work conflict and stress. Int. J. Confl. Manag. 11, 32-55 (2000)

29. Liu, J., Fu, P., Liu, S.: Conflicts in top management teams and team/firm outcomes. Int. J. Confl. Manag. 20, 228-250 (2009)

30. Dimas, I.D., Rocha, H., Rebelo, T., Lourenço, P.R.: A nonlinear multicriteria model for team effectiveness. In: Gervasi, O., et al. (eds.) ICCSA 2016. LNCS, vol. 9789, pp. 595609. Springer, Cham (2016)

31. Rebelo, T., Stamovlasis, D., Lourenço, P.R., Dimas, I., Pinheiro, M.: A Cusp catastrophe model for team learning, team potency and team culture. Nonlinear Dynamics. Psychol. Life Sci. 20, 537-563 (2016) 
32. Ramos-Villagrasa, P.J., Marques-Quinteiro, P., Navarro, J., Rico, R.: Teams as Complex Adaptive Systems: Reviewing 17 Years of Research. Small Gr. Res. 49, 135-176 (2018)

33. Mathieu, J.E., Hollenbeck, J.R., van Knippenberg, D., Ilgen, D.R.: A century of work teams in the Journal of Applied Psychology. J. Appl. Psychol. 102, 452-467 (2017)

34. Guastello, S.J.: Nonlinear dynamics, complex systems, and occupational accidents. Hum. Factors Ergon. Manuf. 13, 293-304 (2003)

35. Thom, R.: Structural stability and morphogenesis: An outline of a general theory of models. W. A. Benjamim, Reading, Massachusetts (1975)

36. Ceja, L., Navarro, J.: Suddenly I get into the zone': Examining discontinuities and nonlinear changes in flow experiences at work. Hum. Relations 65, 1101-1127 (2012)

37. Escartin, J., Ceja, L., Navarro, J., Zapf, D.: Modeling workplace bullying using catastrophe theory. Nonlinear Dyn. Psychol Life Sci 17, 493-515 (2013)

38. Roe, R.A., Gockel, C., Meyer, B.: Time and change in teams: Where we are and where we are moving. Eur. J. Work Organ. Psychol. 21, 629-656 (2012)

39. Santos, G., Costa, T., Rebelo, T., Lourenço, P.R., Dimas, I.: Desenvolvimento Grupal: uma abordagem com base na teoria dos sistemas dinâmicos não lineares Construção/adaptação e validação de instrumento de medida [Group development: A nonlinear dynamical system approach development/adaptation and validation of a measure]. In: Actas do VIII SNIP, Aveiro, Portugal (2013)

40. Vais, R.F.: Validade convergente, validade nomológica e fiabilidade de medidas de um só-item [Convergent validity, nomological validity and reliability of single-item measures]. Master Thesis, FPCE, University of Coimbra, Coimbra, Portugal (2014)

41. Melo, C.: Validade convergente, fiabilidade e validade nomológica de medidas de um só-item: interdependência de tarefa, team learning e satisfao [Convergent validity, reliability, and nomological validity of single-item measures: task interdependence, team learning and satisfaction]. Master Thesis, FPCE, University of Coimbra, Coimbra, Portugal (2015)

42. Gladstein, D.L.: Groups in context: A model of task group effectiveness. Adm. Sci. Q. 29, 499-517 (1984)

43. Rahim, M.A.: A measure of styles of handling interpersonal conflict. Acad. Manage. J. 26, 368-376 (1983)

44. Gilmore, R.: Catastrophe theory for scientists and engineers. Wiley, New York (1981)

45. Poston, T., Stewart, I.: Catastrophe Theory and its Applications. Dover Publications, New York (1978)

46. Guastello, S. J.: Managing emergent phenomena: Non-linear dynamics in work organizations. Erlbaum, New Jersey (2002)

47. Grasman, R.P.P.P., van der Maas, H.L.J., Wagenmakers, E.-J.: Fitting the Cusp Catastrophe in R: A cusp Package Primer. J. Stat. Softw. 32, 1-27 (2009)

48. Burke, M.J., Finkelstein, L.M., Dusig, M.S.: On Average Deviation Indices for Estimating Interrater Agreement. Organ. Res. Methods 2, 49-68 (1999)

49. McGrath, J.E., Arrow, H., Berdahl, J.L.: The study of groups: Past, present, and future, Personal. Soc. Psychol. Rev. 4, 95-105 (2000) 